\section{SMALL DOSES OF A GREAT CHALLENGE: \\ 26 RECOMMENDATIONS FOR PEDIATRIC PHARMACEUTICAL SERVICES IN BRAZIL}

Rafael Santos Santana ${ }^{1}$

Evandro de Oliveira Lupatini ${ }^{1}$

Rodrigo Ramos Sena ${ }^{1}$

Elisangela Costa Lima²

Mirna Poliana Furtado de Oliveira ${ }^{1}$

\section{ABSTRACT}

Three important Brazilian Policies - Medicamentos (PNM), Assistência Farmacêutica (PNAF) e Atenção Integral à Saúde da Criança (PNAISC) — published between 1998 and 2015 emphasized that appropriate technologies should be ensured in pediatric care. In October of 2015 the Pharmaceutical Services (PS) Working Group was established in Pediatrics, by the Ministry of Health, which discussed and proposed guidelines and strategies to make medicines and formulas effective and safe for Brazilian children. This article describes the construction of the first product of the aforementioned group, a document on PS in Pediatrics in Brazil with 8 axes and 26 recommendations published at the end of 2017 after six meetings with 48 experts representing the government, regulatory agencies, associations, scientific societies and universities. It is understood that the dissemination and debate about strategies in the scope of (i) research, (ii) development and production of medicines, (iii) sanitary regulation of medicines, (iv) incorporation of technologies, (v) funding and access to medicines, (vi) transformation, derivation and other actions of manipulation and preparation of pediatric doses, (vii) clinical guidelines, care and safety in the use of medication and (viii) training and education for the rational use of medicines in pediatrics constitute a promising action to open new paths in pediatric care in the country.

\section{INTRODUCTION}

The difficulty of ensuring access to medicines in forms that are appropriate to children, which is already well-known in the reality of pediatric care, has been the subject of frequent publications by researchers in the field. Coelho et al. (2013), for instance, compared the National List of Essential Medicines (Rename - "Relação Nacional de Medicamentos Essenciais", in Portuguese language) of Brazil with the WHO List of Essential Medicines for Children (LMEC - "Lista de Medicamentos Essenciais para Crianças", in Portuguese language) and noted that of the 261 medicines of interest listed in this last publication, $30.3 \%$ are not present in Rename, $11.1 \%$ are in the Brazilian list, but without any formula for children, and $32.3 \%$ are present in some but not all formulas required ${ }^{1}$.

In addition to the problems related to the supply of appropriate medicines for this age group, issues related to the quality of access and its rational use are also of concern. In a population-based survey, it was found that $30 \%$ of the Brazilian children had used medicines in the last 15 days. This percentage increases to $38.4 \%$ when considering only the northeast region, and $48 \%$ when considering only children younger than 2 years old. The prevalence of medicines to treat acute conditions and the use of off-label drugs reinforce the thesis of the lack of adequate therapeutic alternatives ${ }^{2}$.

Different issues are raised to define the causality of problems related to the pediatric therapeutic care. The low number of clinical trials investigating the pediatric drug use results from the lack of sufficient evidence for the medicines registration. The promotion of ethical and technical requirements for the development of studies to ensure research for this public and protection of their intrinsic vulnerability is seen as necessary ${ }^{3}$.

The lack of specific health regulations for the promotion and registration of medicines for pediatric use is also an aspect that must be addressed in the country, as it contrasts with international initiatives by regulatory agencies such as in Europe and the United States, in which advances are observed in regulations of this type and with positive impacts in the increase of registries and reduction of off-label use ${ }^{4}$.

The scarcity of national production also requires that pharmaceutical care policy analyze the adoption of strategies used to promote access to other strategic products, such as importation via international organizations, production by public laboratories or even magistral manipulation, depending on the essentiality of the item or its scale of production ${ }^{5,6}$.

The institution of norms, guidelines and training for the large number of adaptations, pharmaceutical derivations and manipulation techniques carried out daily in Brazilian hospitals is also seen as an emerging need, while trying to adapt medicines and other technologies, in order to promote greater patient safety 7,8 .

The inclusion of themes related to the promotion of rational use of medicines in children in the curricula of health professionals and the carrying out of health education activities with Brazilian Public Health System (Sistema Público de Saúde - SUS) users to warn about the risks of self-medication and overuse of medicines in children are also issues mentioned ${ }^{9,10}$.
1. Departamento de Assistência Farmacêutica do Ministério da Saúde

2. Faculdade de Farmácia. Universidade Federal do Rio de Janeiro

Received: 10/01/2018 Accpted: 07/03/2018

How to cite this article: Santana RS, Lupatini EO, Sena RR, Lima EC, Oliveira MPF. Small doses of a great challenge: 26 recommendations for pediatric pharmaceutical services in Brazil

Rev. Bras. Farm. Hosp. Serv. Saúde, 9(1): 1-3, 2018.

DOI: $10.30968 /$ rbfhss.2018.091.008

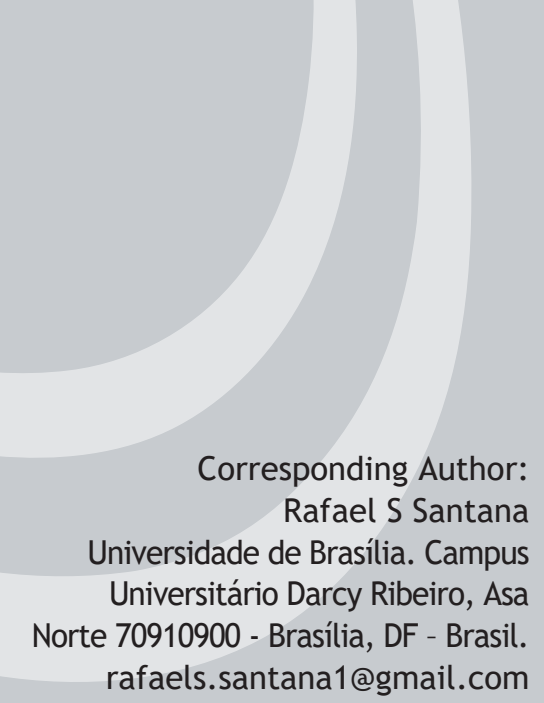




\section{WORK DEVELOPMENT}

To raise the national needs and strategies to promote access to appropriate medicines for Brazilian children, the National Health Department, through the Secretaria de Ciência, Tecnologia e Insumos Estratégicos (SCTIE) Ordinance No. 62, dated from October 15, 2015, established the Working Group (WG) on Pharmaceutical Services in Pediatrics.

Coordinated by the areas of Pharmaceutical Services and Children's Health of the National Health Department, the group had the participation of different managers and technicians of the organ, specialists and researchers on the subject, representatives of scientific societies and professional categories, health organizations, productive area and organized civil society.

The document was developed considering the structure of eight thematic axes, addressing interrelated themes related to pediatric pharmaceutical care, from research, health regulation, the most varied aspects related to medicines such as their development, production, adaptation, incorporation, funding and access in SUS, ranging from issues related to clinical guidelines in pediatrics, to the needs of technologies for health care, in addition to training and qualification of human resources.

During the one-year period, six face-to-face meetings and debates were held at the Pharmaceutical Services Department (BrasíliaDistrito Federal), data collection of scientific literature, expositions and positions of 26 entities and technical areas, with the participation of 48 professionals and specialists from different areas. The work culminated in a technical report containing 26 recommendations, each with its respective strategies described in detail in the publication "Assistência Farmacêutica em Pediatria no Brasil: recomendações e estratégias para a ampliação da oferta, do acesso e do Uso Racional de Medicamentos em crianças Pharmaceutical Services in Pediatrics in Brazil: recommendations and strategies for expanding supply, access and the rational use of Medicines in children" 11

\section{AXES AND RECOMMENDATIONS OF THE REPORT}

\section{Axis I: Research}

1. To clarify and disseminate the ethical aspects related to the participation of the pediatric population in clinical research in the country.

2. To define and periodically review the list of needs and priority studies for the pediatric population in Brazil.

3. To elaborate a Guide with ethical and technical guidelines for conducting research in children, with emphasis on priority studies.

4. To monitor the care provided in Neonatology and Pediatrics to provide the sharing of information and the generation of evidence for the purpose of research and care improvement.

5. To include topics related to Pediatrics in the country's research promotion strategies, including the development of appropriate medicines for children.

\section{Axis II: Development and production of medicines:}

6. To identify the needs of medicines and priority products for pediatric health and mechanisms to encourage their production by the national pharmaceutical industry.

7. To establish mechanisms to encourage the production of medicines appropriate to children by official laboratories.

\section{Axis III: Sanitary regulation of medicines.}

8. To establish mechanisms that allow different analyzes for the registration processes of medicines with pediatric indication, following the initiative of other international agencies.

9. To regulate the presentation of the clinical development plan to the pediatric population at the time of request for registration of new drugs.

10. To publish safety guidelines on excipients that may be used in the formulation of medicines for the pediatric population.

11. To publish efficacy and safety data for medicines for use in the pediatric population.

\section{Axis IV: Incorporation of technologies.}

12. To forward the list of medicines recommended by the Pediatric Pharmaceutical Services WG forknowledge and prioritization of the analyzes of the next editions of the National Relation of Essential Medicines (Rename).

13. To forward and discuss with Brazilian Committee for Health Technology Incorporation (Conitec), as foreseen in art. 21 of Decree No. 8,077, of August 14, 2013, proposals for authorization requests to Brazilian Health Surveillance Agency (Anvisa) for the use of medicines in SUS, whose efficacy, safety and cost-effectiveness are demonstrated in a pediatric population, but that their therapeutic indication is not registered.

14. To include the search for therapeutic alternatives for pediatric conditions, focusing on neglected diseases, as a priority of the work of monitoring the technological horizon (MTH), within the scope of the National Health Department.

15. To introduce the topic of health technologies for pediatrics, focusing on neglected diseases, within the scope of Brazilian Network for Health Technology Assessment (Rebrats), Red de Evaluación de Tecnologías em Salud de las Americas (RedETSA) and other international networks through Pan American Health Organization (PAHO), for the development of studies and guidelines that meet the special needs demanded by the pediatric population.

\section{Axis V: Funding and access to medicines:}

16. To elaborate, within the Pediatric Pharmaceutical Services WG, a list of medicines and priority products for Pediatric Care in Brazil.

17. To structure a network of reference services in manipulation, adaptation or derivation of medicines to meet the needs of Pediatrics in SUS.

18. To ensure information on access to medicines for children in the $\mathrm{Na}$ tional Health Department guidelines.

19. To review the funding mechanisms and access to medicines for children's health, focusing on congenital conditions.

Axis VI: Transformation, derivation and other actions of manipulation and preparation of pediatric doses.

20. Elaboration of a National Technical Document (Pharmacotechnical Memento) with guidelines on transformation, derivation, other actions of manipulation and preparation of doses.

21. To promote studies to elaborate evidences of stability and quality of certain target products of transformation, derivation and manipulation. 
Axis VII: Clinical guidelines, care and safety in the use of medicines.

22. To elaborate protocols for pediatric care within SUS.

23. To review and update the different documents of comprehensive care to the health of the child of the National Health Department.

\section{Axis VIII: Training and education for the rational use of medicines.}

24. To promote activities about the Rational Use of Medicines (RUM) in Pediatrics, aimed at citizens, especially parents, caregivers and educators.

25. To stimulate and promote the presence of a clinical pharmacist with specific training in the routine of health care units of the pediatric population.

26. To train health professionals, especially dentists, nurses, pharmacists and physicians, on the RUM in newborns, infants, children and adolescents.

\section{FINAL CONSIDERATIONS}

Ensuring adequate pharmaceutical care in pediatrics is a multisector and complex challenge. However, pointing out ways and strategies to increase the access and the rational use of medicines for Brazilian children is a pioneering and promising action to guarantee the principle of equity in SUS.

The agenda of the working group has as a perspective the discussion of gaps and problems related to the availability of priority pediatric medicines in Brazil.

\section{FINANCIAL SOURCE}

National Health Department

\section{CONFLICT OF INTERESTS}

Authors have no conflict of interest, including political and / or financial interests associated with patents or property, provision of materials and / or inputs and equipment used in the study by the manufacturers.

\section{AUTHOR'S CONTRIBUTIONS}

RSS, EOL and RRS: were responsible for the conception, analysis paper writing. ECL and MPFO collaborated in literature review and critical revision paper. All authors declare themselves responsible for all aspects of the work in ensuring the accuracy and integrity of any part of the work.

\section{ACKNOWLEDGMENTS}

National Health Department's collaborators and members of Pediatric Pharmaceutical Services WG

\section{REFERENCES}

1. Lutéscia H, Coelho L, Rey LC et al. A critical comparison between the World Health Organization list of essential medicines for children and the Brazilian list of essential medicines (Rename).J Pediatr. 2013, 89(2):171-8.

2. Pizzol T da SD, Tavares NUL, Bertoldi AD et al. Use of medicines and other products for therapeutic purposes among children in Brazil. Rev Saude Publica. 2016, 50( supl 2).
3. Kipper DJ. Ética em pesquisa com crianças e adolescentes: à procura de normas e diretrizes virtuosas. Rev Bioética. 2016, 24(1).

4. Olski TM, Lampus SF, Gherarducci G et al. Three years of paediatric regulation in the European Union. Eur J Clin Pharmacol. 2011, $67(3): 245-52$.

5. Horst MML de L, Soler O. Fundo Estratégico da Organização Pan-Americana da Saúde: mecanismo facilitador para melhorar o acesso aos medicamentos. Rev Panam Salud Pública. 2010, 27(1):43-8.

6. Bastos VD. Laboratórios Farmacêuticos Oficiais e Doenças Negligenciadas: Perspectivas de Política Pública. Rev do BNDES. 2006, 13(25):269-98.

7. Pereira AC de S, Miranda ES, Castilho SR de et al. Medicamentos magistrais em recém-nascidos e crianças hospitalizados. Rev Paul Pediatr. 2016, 34 ${ }^{4}: 403-7$

8. Belela ASC, Pedreira M da LG, Peterlini MAS. Erros de medicação em pediatria. Rev Bras Enferm. 2011, 64(3):563-9.

9. Beckhauser GC, Souza JM de, Valgas C et al. Utilização de medicamentos na Pediatria: a prática de automedicação em crianças por seus responsáveis. Rev Paul Pediatr. 2010, 28(3):262-8.

10. Pfaffenbach $G$. Automedicação em crianças: um problema de saúde pública. Rev Paul Pediatr. 2010, 28(3):260-1.

11. Brasil. Ministério da Saúde. Assistência Farmacêutica em Pediatria no Brasil: recomendações e estratégias para a ampliação da oferta, do acesso e do Uso Racional de Medicamentos em crianças. Brasilia: Ministério da Saúde. 2017. 82p. Disponível em: http://bvsms. saude.gov.br/bvs/publicacoes/assistencia_farmaceutica_pediatria_brasil_recomendacoes.pdf 